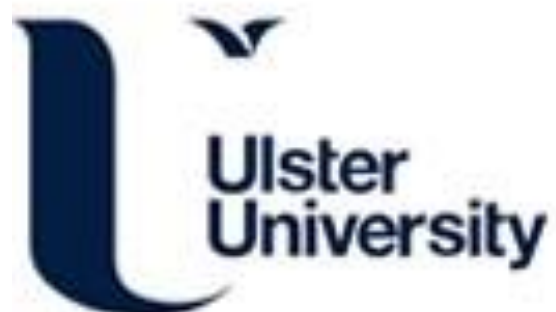

\section{Thermophilic bacteria in cool soils: metabolic activity and mechanisms of dispersal}

Banat, I., Marchant, R., \& Franzetti, A. (2011). Thermophilic bacteria in cool soils: metabolic activity and mechanisms of dispersal. In D. Fontaneto (Ed.), Biogeography of Microscopic Organisms (pp. 43-57). Cambridge University Press.

Link to publication record in Ulster University Research Portal

\section{Published in:}

Biogeography of Microscopic Organisms

Publication Status:

Published (in print/issue): 01/01/2011

\section{Document Version}

Publisher's PDF, also known as Version of record

\section{General rights}

Copyright for the publications made accessible via Ulster University's Research Portal is retained by the author(s) and / or other copyright owners and it is a condition of accessing these publications that users recognise and abide by the legal requirements associated with these rights.

\section{Take down policy}

The Research Portal is Ulster University's institutional repository that provides access to Ulster's research outputs. Every effort has been made to ensure that content in the Research Portal does not infringe any person's rights, or applicable UK laws. If you discover content in the Research Portal that you believe breaches copyright or violates any law, please contact pure-support@ulster.ac.uk. 


\title{
4
}

\section{Thermophilic bacteria in cool soils: metabolic activity and mechanisms of dispersal}

\author{
Roger Marchant ${ }^{1}$, Ibrahim M. BANAT ${ }^{1}$ \\ AND ANDREA FranzetTi ${ }^{2}$ \\ ${ }^{1}$ School of Biomedical Sciences, University of Ulster, Coleraine, \\ Northern Ireland, $U K$ \\ ${ }^{2}$ Department of Environmental Sciences, University of Milano-Bicocca, \\ Milano, Italy
}

\subsection{Introduction}

The biogeographic patterns of plants and animals, i.e. the distribution of biodiversity over space and time has been studied for many years; however, the question whether microorganisms display similar biogeographic patterns remains unanswered (Fenchel et al., 1997). A fundamental assumption that 'everything is everywhere, but the environment selects' was generally promulgated by the Dutch microbiologist Martinus Wilhelm Beijerinck early in the twentieth century and further supported by Baas Becking in 1934. This hypothesis strongly influenced the scientific community throughout the century, leading to widespread acceptance (O'Malley 2008). If

Biogeography of Microscopic Organisms: Is Everything Small Everywhere?, ed. Diego Fontaneto. Published by Cambridge University Press. (C) The Systematics Association 2011. 
the environment is indeed responsible for 'selecting' the organisms in a particular habitat, then we should expect to be able to identify the specific controlling factors for particular organisms. As a consequence of this speculation and as suggested by the literature and experience, the presence of thermophilic bacteria is to be expected in hot environments, from which many of these organisms have been indeed isolated. However, the presence of thermophilic bacteria in cooler environments has been known for many years but few investigations have been carried out to assess their physiology, their ecological roles and to interpret their presence in the framework of biogeographic theory. In 2002 Marchant and colleagues initiated the investigation of the occurrence of highly thermophilic bacteria in cool soil environments, isolating five bacterial strains able to grow aerobically only above $40^{\circ} \mathrm{C}$, a temperature never achieved in these soils. Based on this finding, several questions were raised. What is the frequency of these microorganisms in soils? What kind of microorganisms are they? What is the extent of their diversity? Are they metabolically active? Are there potential transport mechanisms that sustain their presence? This chapter reviews the results of the subsequent research activities carried out at the University of Ulster under the coordination of Professor I.M. Banat and Professor R. Marchant together with some other worldwide collaborating institutions aimed at answering the aforementioned questions.

\subsection{Thermophile community in cool temperate soils}

The occurrence of thermophilic bacteria in soils from different temperate and cool environments was highlighted by Marchant et al. (2002a, 2002b). The investigation focused on soil samples from a range of sites in Ireland, and from one site in Bolivia. Two sites were in Aghadowey, Northern Ireland under established mixed coniferous and deciduous trees with no ground cover plants (Irish Grid reference C881 216), the third site was from an established mixed wet meadow area (Irish Grid reference C881 215). The soil type at both sites was basalt till and the sites had been undisturbed for at least 15 years. The fourth site was in Coleraine, Northern Ireland, Irish Grid reference C843 349 from a cultivated basalt till area. Records of soil temperature at a depth of $50 \mathrm{~mm}$ taken over a 30 -year period in Coleraine (at the University of Ulster meteorological station) indicated that the maximum temperature reached during that time was less than $25^{\circ} \mathrm{C}$. The fourth site was close to the Salar de Uyuni, near the village of Colchani in Bolivia at an altitude of 3653 $\mathrm{m}\left(66^{\circ} 54^{\prime} \mathrm{W}, 20^{\circ} 22^{\prime} \mathrm{S}\right)$. The area was only sparsely covered in vegetation at a distance of $100 \mathrm{~m}$ from the salt plain. All soil samples were taken at a depth of $50 \mathrm{~mm}$ into the mineral layer of the soil. Enrichments were carried out on rich growth medium at $70^{\circ} \mathrm{C}$ and $80^{\circ} \mathrm{C}$ and five pure isolates able to grow at $70^{\circ} \mathrm{C}$ were selected, namely B70, F70, T70, I80 and T80. Other non-investigated thermophilic strains 
have been isolated from a wide range of samples collected in different part of the world (Greece, Italy, Turkey, North America and India). The morphological characterisation of these five strains revealed that the cells were narrow rods (0.5-0.7 $\mu \mathrm{m} \times 1-5 \mu \mathrm{m})$, and showed variable Gram-staining, although transmission electron microscopy analyses revealed Gram-positive cell wall architecture; only B70 showed terminal endospores. The metabolic fingerprinting obtained testing several biochemical parameters resulted in three different metabolic groups constituted by B70 and F70 individually and the cluster T70, T80 and I80 characterised by extensive growth on hydrocarbons. The minimum and the maximum growth temperature under aerobic conditions ranged from 40 to $45^{\circ} \mathrm{C}$ and 75 to $80^{\circ} \mathrm{C}$, respectively. Significant were the short generation times of these organisms at the optimal temperatures (around $75^{\circ} \mathrm{C}$ ) that were less than $30 \mathrm{~min}$. Phylogenetic relationships and taxonomic affiliations of the isolates were performed by means of Amplified Ribosomal DNA Restriction Analyses (ARDRA) and subsequent sequencing of near full-length of the 16S rRNA gene. These molecular tools allowed all the isolates to be assigned to the bacterial domain and to the closest phylogenetic neighbours in the EMBL database. T70, F70 and T80 were closely related ( $>99 \%)$ to Geobacillus thermoleovorans strains while $99 \%$ of similarity was found for B70 and F70 with Geobacillus caldoxylolyticus (EMBL, AF067651) and Bacillus sp. SK-1 (EMBL, AF 326278), respectively. Since the isolation of these thermophilic bacterial strains from enrichment culture provided only evidence of their presence in the soil, quantitative data were obtained by plate counting demonstrating that they were present in high numbers in the soil samples collected in Northern Ireland (1.5-8.8 $\times 10^{4}$ colony forming unit (cfu) per g) and compare to $10 \%$ of the total culturable mesophilic bacteria.

The thermophilic bacterial genus Geobacillus is a relatively recent creation through the separation of a number of existing species of Bacillus and the addition of some new species isolated from deep oil reservoirs (Nazina et al., 2001). The type species for the genus is Geobacillus (Bacillus) stearothermophilus, a longestablished and well-studied species. Subsequent to the publication of the new genus a number of other interesting species have been described from a variety of geothermal and ambient temperature environments (e.g. Sung et al., 2002; Banat et al., 2004; Nazina et al., 2004, 2005).

To describe the biodiversity of the thermophilic community using a higher number of isolates, 52 thermophilic bacterial strains were analysed by ARDRA and sequencing of the $16 \mathrm{~S}$ rRNA gene. The comparison of the profiles obtained using four different restriction endonucleases allowed differentiation of the isolates in 20 different clusters. Eighteen of these clusters were composed of single isolates while 12 isolates exhibited restriction patterns indistinguishable from those of isolate B70, while 19 isolates had identical restriction patterns to T7. The ARDRA analyses and subsequent sequencing of 16S rRNA indicated that 
G. thermoleovorans and G. caldoxylolyticus, accounted for $50 \%$ and $34.6 \%$ respectively. The results of these first studies concerning the presence and diversity of thermophilic bacteria in cool soil clearly demonstrated that there is a great biodiversity of these bacteria within the community and that the Geobacillus genus is dominant (Rahman et al., 2004).

\subsection{Activity of thermophiles in cool environments}

Some species have been described as able to grow anaerobically by denitrification and examination of genome sequence information confirms the presence of all the necessary genes for denitrification activity. For this reason the growth tests reported in the first papers did not completely exclude the possibility that growth at low temperatures could take place anaerobically using nitrate as the final electron acceptor. Thus, the effect of temperature on the denitrification process by G. thermoleovorans T-80 culture was investigated (Marchant et al., 2008). The cultures were incubated at $35,40,45,50,60$ and $70^{\circ} \mathrm{C}$. This assay was conducted in $160 \mathrm{ml}$ serum bottles which were pre-flushed with He. After transferring the culture media $(100 \mathrm{ml})$ the serum bottles were autoclaved at $121^{\circ} \mathrm{C}$ for 30 min. Glucose, yeast extract and nitrate were added resulting in initial concentrations of $1 \mathrm{~g} / \mathrm{l}, 50 \mathrm{mg} / \mathrm{l}$ and $100 \mathrm{mg}$ of nitrogen $\mathrm{N} / \mathrm{l}$, respectively. This assay was conducted using triplicate serum bottles. One serum bottle was used for gas sampling and the other two serum bottles were used for liquid sampling. In addition to the cultures, an abiotic control was also set up with the denitrifying culture media which was amended with nitrate $(100 \mathrm{mg} \mathrm{N} / \mathrm{l}$, without biomass and electron donor).

During the 20 days of incubation nitrate reduction was not observed in the cultures incubated at $35^{\circ} \mathrm{C}$ (Fig 4.1). In all of the cultures the initial acetate concentration was approximately $25 \mathrm{mg} / \mathrm{l}$ which was contributed by the inoculum. For the cultures incubated at $40^{\circ} \mathrm{C}$, after 15 days of lag, complete reduction of nitrate to nitrite was observed in one serum bottle. Nitrate reduction was also observed in the second serum bottle after 15 days of incubation, but the reduction rate was slow, indicating that $40^{\circ} \mathrm{C}$ is the borderline between activity and non-activity. For the cultures incubated at $45^{\circ} \mathrm{C}$, nitrate reduction was observed after 3 days of a lag period. Nitrite reduction was complete within 15 days of incubation in both serum bottles (Fig 4.1). At the end of a 20-day incubation period, all nitrate was reduced to $\mathrm{N}_{2} \mathrm{O}$. For the cultures incubated at $50^{\circ} \mathrm{C}$, nitrate reduction started after 1 day of lag period and complete nitrite reduction required approximately 13 days for both serum bottles. At the end of the 20-day incubation period, all nitrate was reduced to $\mathrm{N}_{2} \mathrm{O}$. For the cultures incubated at $60^{\circ} \mathrm{C}$, immediate nitrate and nitrite reduction took place in both cultures. At the end of the 20-day incubation period, 

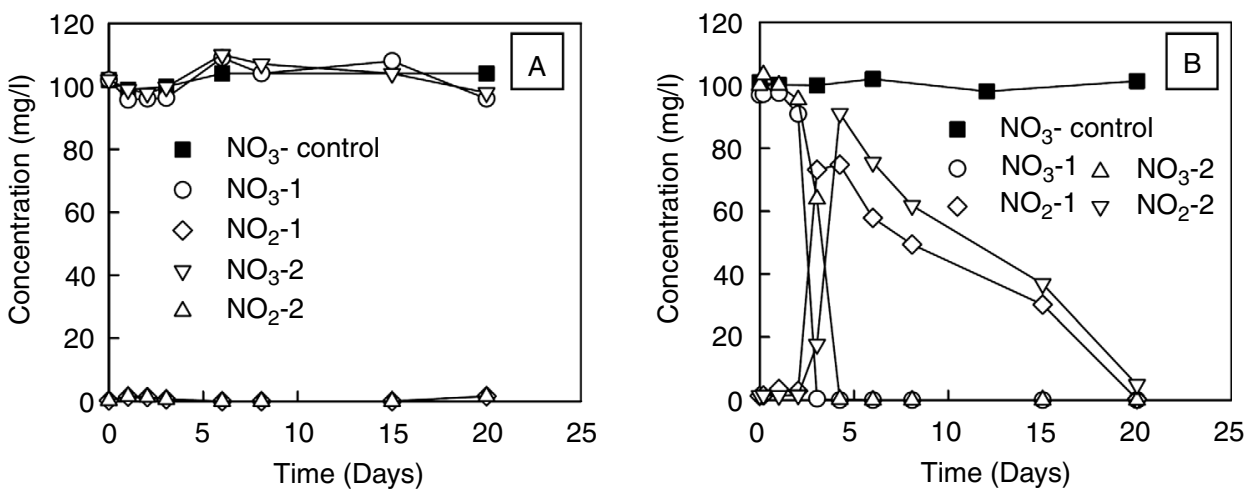

Fig 4.1 Time course of nitrate and nitrite during the denitrification assay with the G. thermoleovorans $\mathrm{T} 80$ culture at $35^{\circ} \mathrm{C}(\mathrm{A})$ and $45^{\circ} \mathrm{C}(\mathrm{B}) ; 1$ and 2 denote replicate 1,2 , respectively. Reproduced with permission from Marchant et al. (2008).

all nitrate was reduced to $\mathrm{N}_{2} \mathrm{O}$. After 15 days of incubation, $\mathrm{N}_{2} \mathrm{O}$ reduction to $\mathrm{N}_{2}$ was observed, but the reduction rate was very low.

The results from the denitrification study gave parallel results to those previously reported for the aerobic activity of Geobacillus, i.e. there is no discernable activity at temperatures below about $40^{\circ} \mathrm{C}$ and certainly none at temperatures close to normal soil temperatures.

The growth experiments with geobacilli both in aerobic and anaerobic conditions were limited by being carried out in a rich laboratory medium using a pure culture as inoculum, thus not taking into account unculturable geobacilli and the soil environment. To overcome this limitation, the use of microcosm experiments and molecular techniques were necessary (Marchant et al., 2008). The Fluorescence In Situ Hybridisation Technique (FISH) was chosen as the tool to quantify the total active geobacilli directly in environmental samples. The FISH technique uses short fluorescence-labelled oligonucleotides that specifically hybridise with the rRNA allowing microscopic discrimination of the different taxa. The fluorescence signal associated with each bacterium reveals both the presence and the activity of the organisms, since a high number of ribosomes are necessary within the cell to provide the signal. Soil collected in Northern Ireland was used in microscosm experiments both with and without the addition of an inoculum of $G$. thermoleovorans 780.

Ten grams of soil collected in Northern Ireland were placed at different temperatures: external ambient; $25^{\circ} \mathrm{C} ; 37^{\circ} \mathrm{C} ; 46^{\circ} \mathrm{C}$ and $60^{\circ} \mathrm{C}$. In another set of microcosms $10 \mathrm{~g}$ of soil, spiked with $1 \mathrm{ml}$ of washed $\mathrm{G}$. thermoleovorans T80 culture in PBS buffer (initial OD $600 \mathrm{~nm}=0.3$ ) was placed at the same temperatures. After 15 days, $1 \mathrm{~g}$ of soil was sampled at each temperature and FISH analysis was carried out. Separation of microorganisms from the soil matrix was achieved according to a 
published protocol (Caracciolo et al., 2005). FISH analyses were carried out on cut filter pieces as previously described (Pernthaler et al., 2001). The oligonucleotide probes used had the following sequences: EUB338 (Amann et al., 1990) - GCT GCC TCC CGT AGG AGT Fluorochrome 5' Fluorescein targeting bacteria and GEOB Tbcil832 (Harmsen et al., 1997) - GGG TGT GAC CCC TCT AAC Fluorochrome 5' Cy3, targeting Geobacillus spp. Images were captured using a Nikon ECLIPSE E 400 epifluorescence microscope. The estimation of microorganisms that bound the probes was determined in at least five randomly selected fields. Using the corrected dilution factor $\left(2 \times 8.22 \times 10^{5}\right)$, the results were referred to $1 \mathrm{~g}$ of soil. Figure 4.2 reports the results of counting total bacteria (EUB probe) and geobacilli (GEOB probe) at different temperatures.

In the unspiked soil the only temperature at which geobacilli are detectable is $60^{\circ} \mathrm{C}$ both after 15 days and 4 months. At this temperature $0.9 \times 10^{6}$ active geobacilli/g of soil were detected after 15 days while $0.7 \times 10^{6} / \mathrm{g}$ of soil were still present after 4 months representing $6 \%$ and $9 \%$ of the total active bacterial community, respectively. These data indicated that at this temperature geobacilli in the soil are metabolically active but they do not effectively grow, thus indicating that $10^{6}$ is a good estimate of the presence of total (culturable and unculturable) geobacilli in one gram of soil sample. In the T80 spiked microcosms, after 15 days geobacilli were detected at all tested temperatures; this can be explained by the hypothesis that $G$. thermoleovorans is able to maintain a certain number
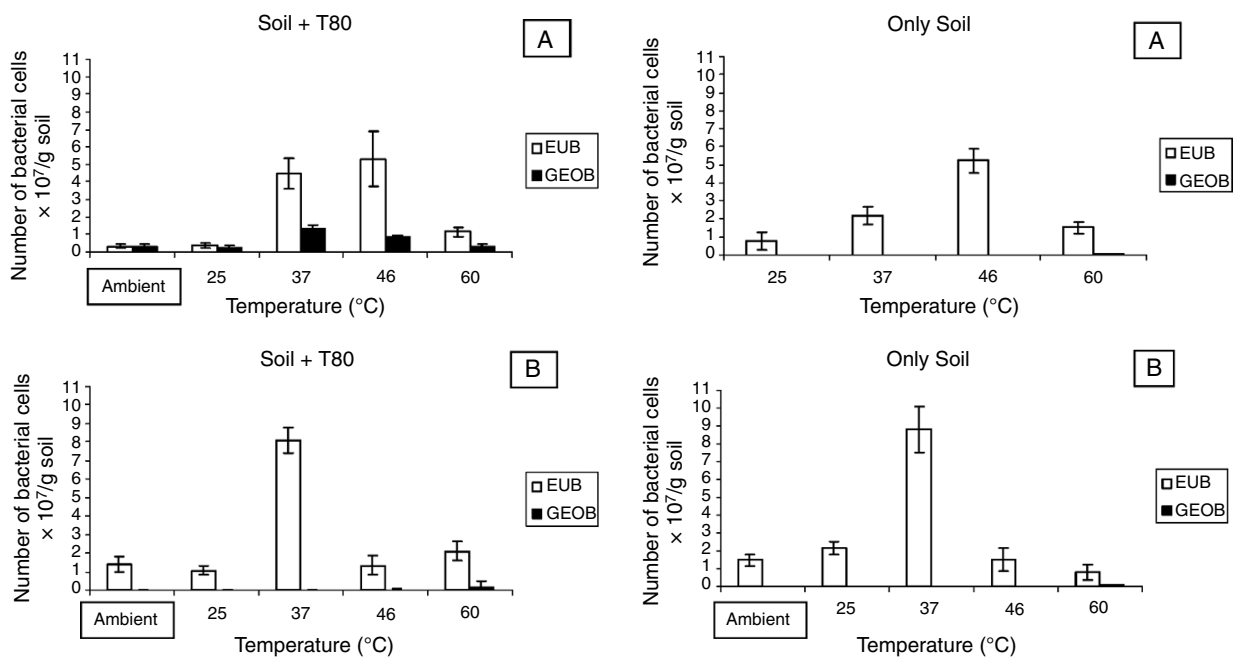

Fig 4.2 Counts of FISH-stained cells using a bacterial probe (EUB) and a specific Geobacillus probe (GEOB) in soil microcosms after 15 days (A) and 4 months (B). Graphs on the left represent the microcosms spiked with $G$. thermoleovorans $\mathrm{T} 80$, while the graphs on the right the microcosms without addition. Reproduced with permission from Marchant et al. (2008). 


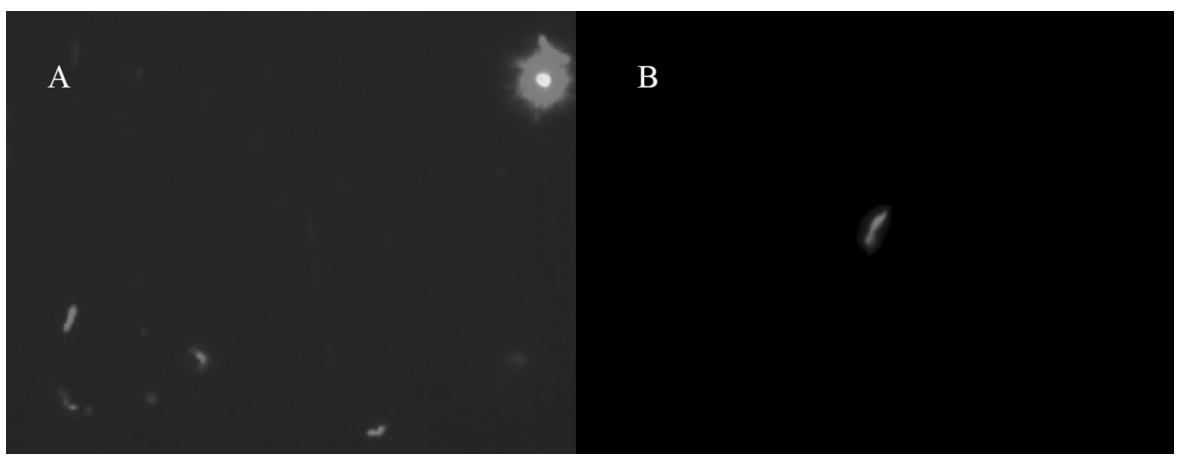

Fig 4.3 Bacterial cell using a Geobacillus (GEOB) probe in T80 spiked microcosm at $46^{\circ} \mathrm{C}$ (A) and $60^{\circ} \mathrm{C}(\mathrm{B})$.

of ribosomes over the first two weeks at a wide range of temperatures. After 4 months geobacilli were countable only at $46^{\circ} \mathrm{C}$ and $60^{\circ} \mathrm{C}$ reaching a value of $1.3 \times 10^{6} / \mathrm{g}$ of soil at $60^{\circ} \mathrm{C}$ which is comparable with the unspiked microcosms. Figure 4.3 shows Geobacillus cells detected by GEOB probe in T80 spiked microcosms at $46^{\circ} \mathrm{C}$ and $60^{\circ} \mathrm{C}$.

FISH experiments confirmed the relationship between growth and temperature obtained in liquid growth experiments both in aerobic and anaerobic conditions. In the soil total thermophilic geobacilli seem to be inactive below $40^{\circ} \mathrm{C}$, at least as detected by FISH technique.

Another proof of this behaviour under in situ conditions has been obtained by analysing the expression of the alkane mono-oxygenase gene (alkB) by thermophilic soil bacteria (Marchant et al., 2006). Many geobacilli and particularly G. thermoleovorans are well-known hydrocarbon degraders with high similarity with mesophilic bacteria for the sequences of one of the key enzymes for alkane biodegradation (i.e. alkB: alkane-1-mono-oxygenase). In this study, soil microcosms were established in glass universals using glass wool as an interface between $1 \mathrm{ml}$ $\mathrm{n}$-hexadecane and $10 \mathrm{~g}$ of soil. The microcosms were then incubated for up to 14 days at room temperature, and $25,30,37$ and $55^{\circ} \mathrm{C}$. A further soil microcosm was also inserted in situ just below the surface soil layer in the natural environment for the same period of time. Control microcosms containing no alkane were also prepared. On soil samples, RT-PCR analyses were performed.

A positive detection of the expression of $a l k \mathrm{~B}$ gene by RT-PCR was detected only in soil samples kept for some days at least at $55^{\circ} \mathrm{C}$ in the presence of the hydrocarbon. It was also demonstrated that alkB production did not originate from mesophilic microorganisms. The same results were obtained using pure cultures of G. thermoleovorans T80. These results highlighted the specificity of thermophiles for the degradation of hydrocarbons. It is worth noting that in soil 
samples taken from a cool region that had never been contaminated with hydrocarbons, raising the temperature is the condition in which the expression of alkB gene is induced in the microbial community in the presence of added hydrocarbons. This property was further investigated as an innovative bioremediation alternative (Perfumo et al., 2007). In this study, soil samples were collected in an undisturbed area in Northern Ireland unpolluted with hydrocarbons. Microcosm experiments were prepared in sterile bottles containing $5 \mathrm{~g}$ of soil with $2 \%(\mathrm{v} / \mathrm{w})$ n-hexadecane added. Five different bioremediation techniques were tested: (1) degradation potential by indigenous microorganisms (natural attenuation); (2) supplementation with inorganic nutrients (Biostimulation); (3) supplementation with microbial surfactants (Biosolubilisation); (4) supplementation with selected hydrocarbon-degrading bacteria (Bioaugmentation); and (5) Biostimulation + Biosolubilisation + Bioaugmentation. Sterile soil with no amendments was used as an abiotic control. Microcosms were incubated in the dark at $60^{\circ} \mathrm{C}$ and at room temperature (approximately $18^{\circ} \mathrm{C}$ ), and monitored at $0,5,15,30$ and $40 \mathrm{~d}$ for the estimation of hydrocarbon content by gas chromatography and the bacterial populations. Results showed that for all the conditions the biodegradation of the hydrocarbon was almost doubled at $60^{\circ} \mathrm{C}$ compared with room temperature. It is already well established that one of the limiting factors in bioremediation is the bioavailability of the contaminants. Particularly, for slightly soluble compounds, such as hydrocarbons, the rate of mass transfer to cells limits the overall biodegradation rate (Boopathy, 2000). Increasing temperature leads to a decreased viscosity, higher solubility and faster diffusion of hydrophobic contaminants to the cell thus enhancing the biodegradation rates.

The results reported above concerning growth and activity of thermophiles at different temperatures seem to demonstrate unequivocally that no growth and activity can be postulated for thermophilic bacteria in cool soils. However, the most unexpected and important results came from simple long-term pure culture growth experiments in liquid medium. Sealed replicate universal tubes containing $10 \mathrm{ml}$ of nutrient broth were inoculated with $G$. thermoleovorans and incubated at $4{ }^{\circ} \mathrm{C}, 25^{\circ} \mathrm{C}, 37^{\circ} \mathrm{C}, 46^{\circ} \mathrm{C}$ and $60^{\circ} \mathrm{C}$ for 9 months. The tubes were observed periodically for visible signs of growth. Tubes incubated at a temperature of $40^{\circ} \mathrm{C}$ rapidly showed evidence of growth; even after 9 months, the tubes incubated at $25^{\circ} \mathrm{C}$ showed no visible evidence of growth, but once transferred to $60^{\circ} \mathrm{C}$ showed visible growth after $24 \mathrm{~h}$ indicating that viable thermophile cells remained in the culture. Surprisingly, after 9 months, the tubes maintained at $4{ }^{\circ} \mathrm{C}$ showed visible evidence of extensive growth. To avoid misinterpretation of the results due to contamination by psychrophilic bacteria, subcultures were taken from these tubes and incubated at $70^{\circ} \mathrm{C}$, showing that the growth was that of a thermophile. Furthermore microscopic observation and 16S rRNA sequencing confirmed that the organism was identical to the original inoculum. 


\subsection{Transport mechanisms and potential sources}

The establishment of no or low activity of thermophiles in cool soils led to the speculation that they could be transported from warmer places in which these organisms are better able to grow and divide. Two potential sources for thermophiles were hypothesised: a short-range transport by wind from the local environment in which high temperature conditions can transiently occur (heating facilities, composting plants ...) and a long-range transport by clouds and rainwater from warmer geographic regions. Both quantitative and qualitative analyses of the bacterial populations in rainwater and air in Northern Ireland were carried out (Marchant et al., 2008). Air samplings were carried out from 6 until 30 October 2005 both for counting and isolation of thermophilic microorganisms and weather conditions were recorded. Fifty rainwater samples for thermophilic bacteria counting were collected from 1 February until 14 May 2004, while eight samples for isolation were collected from 10 October until 2 November 2005. Wind direction, wind speed and rainfall were further recorded during samplings. Fourteen rainwater and fourteen airborne microorganisms were isolated that were able to grow at $70^{\circ} \mathrm{C}$. Partial $16 \mathrm{~S}$ rDNA sequences (at least 900 bases) were determined to assess the microbial communities of thermophilic bacteria in air and in rainwater and compare them with the already published characterisation of the thermophilic population in soil (Marchant et al., 2002b). Figure 4.4 shows the phylogenetic tree built with the sequences of all the isolates and the sequences of some type strains that showed more than $97 \%$ sequence similarity with the isolates. In the rainwater community, all 14 isolates are assigned to Geobacillus; particularly, 12 of them have, as nearest phylogenetic neighbours, Geobacillus thermodenitrificans DSM 465T and Geobacillus subterraneus T34T while two stand very close to Geobacillus stearothermophilus DSM 22TT, Geobacillus thermocatenulatus DSM 730T, Geobacillus vulcani 3S-1T (Nazina et al., 2004), Geobacillus kaustophilus NCIMB 8547T and Geobacillus thermoleovorans DSM 5366T.

In the air community, seven isolates are assigned to Bacillus, one to Ureibacillus and six to Geobacillus. Two air isolates (A9.11 and A9.13) showed very high similarity (> 99\%) with a thermophilic environmental isolate submitted as Bacillus aestuarii (GenBank: AB062696) that was included in the tree. Considering all isolates, four Operational Taxonomic Units (OTUs) have been defined (each OTU comprised sequences that shared $>97 \%$ sequence identity) by distance analysis. The two communities showed very different distributions of their isolates along the OTUs. All the isolates of the rainwater community belong to OTU 1, while in the air community, six isolates belong to OTU 1, one to OTU 2, three to OTU 3 and four to OTU 4. Furthermore, only in the air samples were three microorganisms isolated able to grow at $60^{\circ} \mathrm{C}$ but not at $70^{\circ} \mathrm{C}$, which were morphologically 


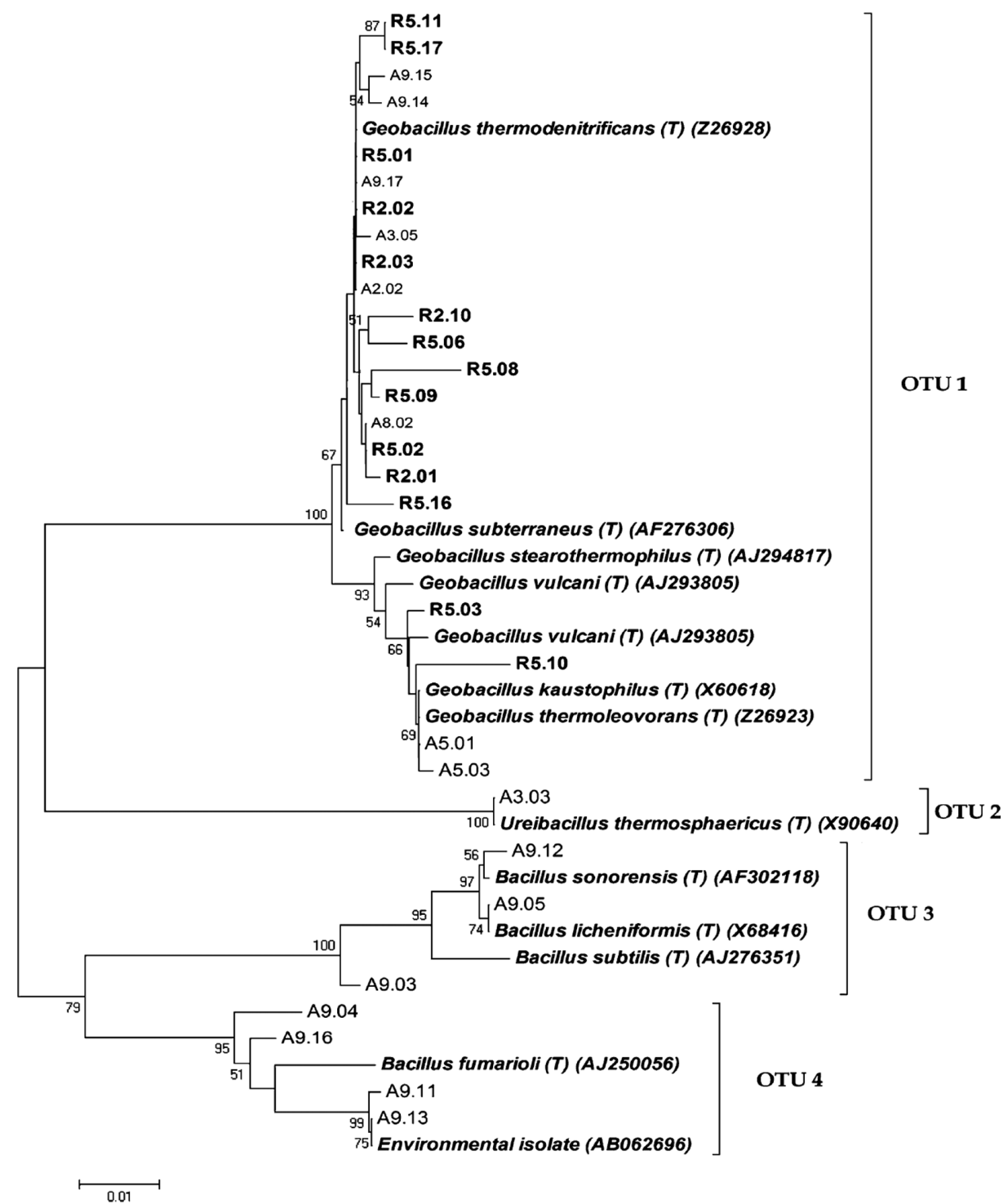

Fig 4.4 Unrooted phylogenetic tree based on 16S rRNA gene comparison showing the position of rainwater (bold) and air isolates and the type strains most closely related (italic). Bootstrap probability values less than $50 \%$ were omitted from the figure. The scale bar indicates substitutions per nucleotide position. The GenBank accession numbers of type strains are in parentheses. Reproduced with permission from Marchant et al. (2008).

identified as thermotolerant Actinomycetales. This distribution led to the conclusion that the rainwater community of thermophilic bacteria is characterised by a lower biodiversity than the air one. To confirm this lack of biodiversity in rainwater and to avoid any influence due to seasonality, another two rainwater 
samplings were carried out in January 2006. Ten microorganisms were isolated and 8 showed very high similarity with Geobacillus thermodenitrificans DSM 465T while two isolates shared $>99 \%$ sequence similarity with Ureibacillus thermosphericus $\mathrm{P}-11 \mathrm{~T}$. The structure of the rainwater community seems to be more similar to the structure of the soil community than does the air community suggesting that rainwater deposition could be a mechanism that sustains the thermophilic community in these soils.

For quantitative analyses, thermophilic bacteria were determined by the Most Probable Number (MPN) technique at $70^{\circ} \mathrm{C}$ in liquid medium, while airborne thermophiles were quantified by direct sampling and growth at $70^{\circ} \mathrm{C}$ on agar-rich medium. For air samplings a mean value of $1.55 \mathrm{cfu} / 1000 \mathrm{l}$ of air was obtained. For rainwater counting, thermophilic bacteria were found in detectable numbers only in nine samples. The mean value of these nine samples was 8.5 cells $/ 100 \mathrm{ml}$, while considering the whole amount of sampled water, the mean was 1.1 cells/100 $\mathrm{ml}$. Furthermore, from rainfall data and MPN counting, it is possible to calculate the total number of thermophilic microorganisms that have been deposited onto $1 \mathrm{~m}^{2}$ of soil during the sampling period; a value of $9.5 \times 10^{3}$, or an average of 140 for each millimetre of rainfall. Considering an average rainfall value in this part of Ireland of $1000 \mathrm{~mm}$ per year, the total annual input of thermophilic microorganisms from rainwater to soil could be estimated as $1.4 \times 10^{5} / \mathrm{m}^{2}$ of soil surface. Marchant et al. (2002a) found values of thermophiles for this area ranging from $1.5-8.8 \times 10^{4} \mathrm{cfu} / \mathrm{g}$ soil at $50 \mathrm{~mm}$. Also considering $50 \mathrm{~mm}$ as the maximum depth affected by rainwater deposition the number of thermophiles on $1 \mathrm{~m}^{2}$ of soil ranges from 0.75 to $4.4 \times 10^{9} \mathrm{cfu} / \mathrm{m}^{2}$. This means that only a small fraction $\left(0.3-2 \times 10^{-5}\right)$ of thermophiles can be replaced yearly by rainwater deposition. Therefore, assuming the rainwater deposition as the only source of thermophiles, it would not be possible to maintain a high and constant viable population of thermophiles without their growth or survival in the soil.

Although the studies of thermophilic geobacilli in rainwater provided an important insight into the origin of these organisms in cool soils they still did not identify the ultimate origin of the microorganisms. Since the advent of satellite imaging it has become apparent that considerable global transport of dust occurs and that one of the major origins for these dust storms is the Sahara/ Sahel region of Africa (Griffin et al., 2002). Dust from this region travels northwards over the Mediterranean countries where it is often deposited in a dry form. Further movement then takes the dust over northern Europe and across the Atlantic to the Caribbean and southern USA. Dry dust deposition does not occur in northern Europe but the dust is precipitated in rainfall. To test the hypothesis that the ultimate origin of thermophilic geobacilli in rainfall in northern Europe is Saharan dust storms, samples of dry dust were collected and were examined for the presence of thermophilic geobacilli using culture methods (Perfumo and Marchant, 2010). Samples of dust collected in Turkey and Greece following two 
distinct desert storm events contained viable thermophilic organisms of the genus Geobacillus, namely G. thermoglucosidasius and G. thermodenitrificans, and the recently reclassified Aeribacillus pallidus (formerly Geobacillus pallidus). These results provided evidence that African dust storms create an atmospheric bridge between distant geographic regions and that they are also probably the source of thermophilic geobacilli later deposited over northern Europe by rainfall or dust plumes themselves. The same organisms (99\% similarity in the 16S rDNA sequence) were found in dust collected in the Mediterranean region and inhabiting cool soils in Northern Ireland (Perfumo and Marchant, 2010).

\subsection{Conclusions}

In recent years, the Baas Becking hypothesis has provoked intense discussions and some investigations have been carried out to verify it. A recent review has drawn attention to the two components of biogeographic distribution, the province and the habitat (Hughes Martiny et al., 2006). The province represents the legacy of historical events while the habitat represents the existing environment for the organism. This review identified four possible hypotheses to describe microbial biogeography patterns and attempted to differentiate between the possible alternatives with the aim of evaluating whether the biogeographic pattern of macroorganisms can be applied to microorganisms. The first alternative is that microorganisms are randomly distributed over space while in a second hypothesis only environmental conditions affect the geographic distribution of microorganisms. The latter is the Baas Becking hypothesis: 'everything is everywhere, but the environment selects'. In the third hypothesis, the present distribution of microorganisms is influenced only by historical events, while the fourth one allows both legacy of past historical events and present environmental conditions to influence the biogeography of microorganisms. The results of some investigations led the authors to conclude that the environment actually selects and shares with the legacy of historical events the responsibility for the spatial variation of microorganisms. However, as reported by the authors of the review, the idea that all the attributes of the organism that can potentially influence their spatial distribution can be described allometrically does not capture the complexity of the microbial world. Dispersal, colonisation, extinction and diversification are processes that shape the biogeography of the organisms and the wide metabolic diversity among Bacteria, Archaea and microscopic Eukarya makes it difficult to find a simple correlation between size and the rate of these processes. For instance, the dispersal rate is strongly influenced by tolerance to the extreme environmental conditions that microorganisms experience during passive transport. Spore-forming bacteria 
have an advantage in being transported for long distances. Thus, the spatial dispersal of microorganisms depends not only on their size, but also on their specific attributes.

The results reported in this chapter report the presence and activity of bacteria in an environment that potentially does not allow their growth due to the low temperatures. Since it has been demonstrated that Geobacilli are extremely resistant to space vacuum, UV radiation and gamma-ray exposure and are the only microorganisms selected from hot environments under these extreme conditions (Saffary et al., 2002), it can be hypothesised that members of the genus Geobacillus are present wordwide due to this resistance to stress. In this sense, the assumptions of the Baas Becking hypothesis hold true for this kind of bacterium. Moreover, for geobacilli the selection of the cold environments seems not to hold since at least a slow growth is supposed to sustain their large population in cold soils. This growth is probably explained by the balance of growth and death rate at low temperatures. In geobacilli, at temperatures above $40^{\circ} \mathrm{C}$, the growth rate exceeds the death rate, and this differential increases up to $60^{\circ} \mathrm{C}$; at temperatures between ambient and $37^{\circ} \mathrm{C}$, the death rate is higher than the growth rate, preventing any increase in biomass in freshly inoculated cultures (Pavlostathis et al., 2006). Thus, it can be supposed that the growth at $4^{\circ} \mathrm{C}$ over protracted time periods can be explained by a low growth rate but an even lower death rate. These specific features make members of the genus Geobacillus cosmopolitan microorganisms.

\section{References}

Amann, R.I., Binder, B.J., Olson, R.J. et al. (1990). Combination of 16S rRNAtargeted oligonucleotide probes with flow cytometry for analyzing mixed microbial populations. Applied Environmental Microbiology 56, 1919-1925.

Banat, I.M., Marchant, R., Rahman, T.J. (2004). Geobacillus debilis sp. nov., a novel obligately thermophilic bacterium isolated from a cool soil environment, and reassignment of Bacillus pallidus to Geobacillus pallidus comb. nov. International Journal of Systematics and Evolutionary Microbiology 54, 2197-2201.
Boopathy, R. (2000). Factors limiting bioremediation technologies. Bioresource Technology 74, 63-67.

Caracciolo, A.B., Grenni, P., Cupo, C., Rossetti, S. (2005). In situ analysis of native microbial communities in complex samples with high particulate loads. FEMS Microbiology Letters 253, 55-58.

Fenchel, T., Esteban, G.F., Finlay, B.J. (1997). Local versus global diversity of microorganisms: cryptic diversity of ciliated protozoa. Oikos 80, 220-225.

Griffin, D.W., Kellogg, C.A., Garrison, V.H., Shinn, E.A. (2002). The global transport of dust. American Scientist 90, 228-235. 
Harmsen, H., Prieur, D., Jeanthon, C. (1997). Group-specific 16S rRNAtargeted oligonucleotide probes to identify thermophilic bacteria in marine hydrothermal vents. Applied and Environmental Microbiology 63 , 4061-4068.

Hughes Martiny, J.B., Bohannan, B.J.M., Brown, J.H. et al. (2006). Microbial biogeography: putting microorganisms on the map. Nature Reviews Microbiology 4, 102-112.

Marchant, R., Banat, I.M., Rahman, T.J., Berzano, M. (2002a). The frequency and characteristics of highly thermophilic bacteria in cool soil environments. Environmental Microbiology $\mathbf{4}$, 595-602.

Marchant, R., Banat, I.M., Rahman, T.J., Berzano, M. (2002b). What are high temperature bacteria doing in cold environments? Trends in Microbiology 10, 120-121.

Marchant, R., Sharkey, F.H., Banat, I.M., Rahman, T.J., Perfumo, A. (2006). The degradation of n-hexadecane in soil by thermophilic geobacilli. FEMS Microbiology Ecology 56, 44-54.

Marchant, R., Franzetti, A., Pavlostathis, S.G. et al. (2008). Thermophilic bacteria in cool temperate soils: are they metabolically active or continually added by global atmospheric transport? Applied Microbiology and Biotechnology 78, 841-852.

Nazina, T.N., Tourova, T.P., Poltaraus, A.B. et al. (2001). Taxonomic study of aerobic thermophilic bacilli: descriptions of Geobacillus subterraneus gen. nov., sp. nov. and Geobacillus uzenensis sp. nov. from petroleum reservoirs and transfer of Bacillus stearothermophilus, Bacillus thermocatenulatus, Bacillus thermoleovorans, Bacillus kaustophilus,
Bacillus thermoglucosidasius

and Bacillus thermodenitrificans

to Geobacillus as the new

combinations G. stearothermophilus,

G. thermocatenulatus,

G. thermoleovorans, G. kaustophilus,

G. thermoglucosidasius and

G. thermodenitrificans. International

Journal of Systematics and Evolutionary

Microbiology 51, 433-446.

Nazina, T.N., Lebedeva, E.V., Poltaraus,

A.B. et al. (2004). Geobacillus gargensis

sp. nov., a novel thermophile from a

hot spring, and the reclassification

of Bacillus vulcani as Geobacillus

vulcani comb. nov. International

Journal of Systematics and Evolutionary Microbiology 54, 2019-2024.

Nazina, T.N., Sokolova, D.S., Grigoryan, A.A. et al. (2005). Geobacillus jurassicus sp. nov., a new thermophilic bacterium isolated from a hightemperature petroleum reservoir, and the validation of the Geobacillus species. Systematic and Applied Microbiology 28, 43-53.

O'Malley, M.A. (2008). Everything is everywhere: but the environment selects: ubiquitous distribution and ecological determinism in microbial biogeography. Studies in History and Philosophy of Biological and Biomedical Sciences 39, 314-325.

Pavlostathis, S.G., Marchant, R., Banat, I.M., Ternan, N.G., McMullan, G. (2006). High growth rate and substrate exhaustion results in rapid cell death and lysis in the thermophilic bacterium Geobacillus thermoleovorans. Biotechnology and Bioengineering 95, 84-95.

Perfumo, A., Marchant, R. (2010). Global transport of thermophilic bacteria in atmospheric dust. Environmental Microbiology Reports 2, 333-339. 
Perfumo, A., Banat, I.M., Marchant, R., Vezzulli, L. (2007). Thermally enhanced approaches for bioremediation of hydrocarbon-contaminated soils. Chemosphere 66, 179-184.

Pernthaler, J., Glöckner, F-O., Schönhuber, W., Amann, R. (2001). Fluorescence in situ hybridization (FISH) with rRNAtargeted oligonucleotide probes. Methods in Microbiology 30, 207-226.

Rahman, T.J., Marchant, R., Banat, I.M. (2004). Distribution and molecular investigation of highly thermophilic bacteria associated with cool soil environments. Biochemical Society

Transactions 32, 209-213.

Saffary, R., Nandakumar, R., Spencer, D. et al. (2002). Microbial survival of space vaccum and extreme ultraviolet irradiation: strain isolation and analysis during a rocket flight. FEMS Microbiology Letters 215, 163-168.

Sung, M.-H., Kim, H., Bae, J.-W. et al. (2002). Geobacillus toebii sp nov., a novel thermophilic bacterium isolated from hay compost. International Journal of Systematics and Evolutionary Microbiology 52, 2251-2255. 

PART III

Unicellular eukaryotes 
